\title{
Redirection of CD4+ and CD8+ T lymphocytes via an anti-CD3 $\times$ anti-CD19 bi-specific antibody combined with cytosine arabinoside and the efficient lysis of patient-derived B-ALL cells
}

\author{
Dongmei Fan ${ }^{1+}$, Wei $\mathrm{Li}^{2 \dagger}$, Yuqi Yang ${ }^{3}$, Xiaolong Zhang ${ }^{1}$, Qing Zhang ${ }^{1}$, Yan Yan ${ }^{1}$, Ming Yang ${ }^{\text {* }}$,
} Jianxiang Wang ${ }^{1 *}$ and Dongsheng Xiong ${ }^{1 *}$

\begin{abstract}
Background: B-acute lymphoblastic leukemia (B-ALL) is derived from B cell progenitors. Recently, the development of appropriate combinations of chemotherapy and immunotherapy represents a promising approach for eliminating cancer. We previously constructed an anti-CD3 $\times$ anti-CD19 bi-specific antibody in a diabody configuration and its disulfide-stabilized format (ds-diabody). The combination of the diabody or ds-diabody and Ara-C was highly effective in enhancing the cytotoxicity of $T$ cells against the CD19+ human leukemia cell-line, Nalm-6, both in vitro and in vivo. This study verified whether B-ALL patient-derived cells were sensitive to the diabody or ds-diabody and low-dosage Ara-C combination.

Methods: This study aimed to detect the B7 family members B7.1 (CD80) and B7.2 (CD86) that were expressed in B-ALL patient-derived cells pre-treated by $\operatorname{Ara}-\mathrm{C}(0.25 \mu \mathrm{M})$ and to determine the targeted killing ability of $\mathrm{T}$ cell subtypes induced by the diabody or ds-diabody combination with Ara-C both in vitro and in vivo. We also determined the levels of the cytokines that were released by activated CD4+ or CD8+ $T$ cells during therapy.

Result: Low-dose Ara-C enhanced CD80 and CD86 expression in nearly $50 \%$ of specimens of B-ALL patient-derived cells. A combination of diabody or ds-diabody and Ara-C enhanced T cell against B-ALL cells in vitro and in vivo. Both CD8+ and CD4+ T cells were potently activated. Expression of CD25 and CD69 was augmented equally by CD4+ or CD8+ T cells. However, CD8+ T cells made the major contribution by redirecting target cell lysis in a granzyme B and perforin-dependent mechanism. CD4+ T cells played an important immunomodulatory role by secreting IL2. Consequently, IL3, IL6, TNFa, and IFNy were also released by CD4+ or CD8+ T cells following diabody-mediated T cell activation.

Conclusion: T cell therapy induced by diabody or ds-diabody combined with low dose of Ara-C was effective against cancer cell-lines and in clinical trials. In vivo, the ds-diabody was more efficient than its parent diabody due to its enhanced stability.
\end{abstract}

Keywords: Bi-specific antibody, Diabody Anti-CD3, Anti-CD19, Disulfide crosslinks, B-ALL, Cancer immunotherapy

\footnotetext{
*Correspondence: my1970@163.com; yzzhangtj@126.com; dsxiong@ihcams.

ac.cn

${ }^{\dagger}$ Equal contributors

'State Key Laboratory of Experimental Hematology, Institute of Hematology and Hospital of Blood Diseases, Chinese Academy of Medical Sciences and Peking Union Medical College, Tianjin 300020, People's Republic of China Full list of author information is available at the end of the article
} 


\section{Introduction}

B-lymphoblastic leukemia/lymphoma, also known as B-acute lymphoblastic leukemia (B-ALL), is a hematological malignancy that is derived from B cell progenitors. B-ALL occurs at any age but is predominantly seen in children $[1,2]$. Risk-adapted intensive chemotherapy is effective in treating most children with B-ALL, but this approach is less successful in adults [3]. Chemotherapy is traditionally considered to kill cancer cells via direct cytotoxicity. Therefore, these drugs often generate severe side effects in patients such as nausea, vomiting, bone marrow depression, and alopecia. A common cause of treatment failure includes acquired resistance of tumor cells to conventional chemotherapy [4]. Targeted therapy represents a promising alternative to conventional chemotherapy in various types of cancer [5-8]. Monoclonal antibodies have played a major role in lymphoma therapy for more than a decade [9-11]. A series of monoclonal antibodies (mAbs) that specifically target different tumor cell surface antigens have been tested in both experimental and clinical studies [12, 13]. The anti-CD20 $\mathrm{mAb}$, rituximab, has substantially improved clinical outcomes in Burkitt's lymphoma/leukemia and is currently applied in de novo B-precursor ALL [14]. The MoAbs that are directed against CD22, linked to cytotoxic agents including, either to calicheamicin (i.e., inotuzumab ozogamicin) or bacterial toxins (e.g., epratuzumab) are explored in refractory/relapsed childhood and adult ALL [15]. A novel anti-CD19 monoclonal antibody, GBR 401, exerts a potent in vitro and in vivo cytotoxic activity against primary samples from patients representing various B cell malignancies [16]. In addition, novel immunotherapeutics targeting B cell receptor signaling (e.g., ibrutinib) [17], T cell receptor (e.g., CART19) [18], and NK cells (e.g., AFM13) [19] are being developed.

In addition to the development of therapeutics for new targets, another approach to improve current antibody therapy is the development of bi-specific antibodies (bsAbs). In principle, bsAbs are generated by the fusion of the minimal binding domains (fragment variable) of two $\mathrm{mAbs}$ via flexible peptide linkers. By simultaneous binding to the activating CD3 complex and a tumor-associated surface antigen (TAA), they can trigger efficient $\mathrm{T}$ cellmediated tumor cell lysis in a TCR- and MHCindependent manner [20-24]. Various formats of bsAbs engineered to redirect cytotoxic T cells (CTLs) have demonstrated therapeutic efficacy in preclinical and clinical settings by binding to tumor-associated antigens. The potential of this mode of therapy was demonstrated preclinically in hematopoietic cancers [25, 26]. For example, the CD19 $\times$ CD3 BiTE (blinatumomab or MT103) has been studied in phase II trials for B-ALL [27].

Moreover, some studies have shown that chemotherapy might also enhance the immune response of the host against the tumor itself [28]. As mounting evidence suggests that the therapeutic efficacy of some chemotherapeutic drugs relies on their capability to interact with the immune system, the development of appropriate combinations of chemotherapy and immunotherapy represents a promising approach for eliminating cancer cells [29, 30].

Recently, we constructed a novel bi-specific antiCD3 $\times$ anti-CD19 diabody and its disulfide-stabilized format (ds-diabody) [31]. The cytotoxicity of these two diabodies showed no dramatic differences in vitro. However, in vivo, the ds-diabody was more efficient than its parental diabody in inducing tumor cell lysis because of its increased stability [31]. Osada et al. used chemotherapy to sensitize tumor targets to cytotoxicity mediated by bi-specific antibodies that were directed to $\mathrm{T}$ cells [32]. Tretter reported that taxanes could sensitize BiAb killing [33].

In the present study, Ara-C up-regulated CD80 expression on the CD19+ human leukemia cell-line Nalm-6. A combination of the diabody plus Ara-C induced greater CTL activity against Nalm-6 cells both in vitro and in vivo [34]. Ara-C, which is one component of the most widely used regimens for treating ALL, was used in this study at a low dose.

This study aimed to verify whether B-ALL patientderived cells were also sensitive to combined treatment with the diabody or ds-diabody and low-dose Ara-C. The purpose of the study was to detect the B7 family members B7.1 (CD80) and B7.2 (CD86) that were expressed in B-ALL patient-derived cells following pretreatment with Ara-C and to determine whether the combination of the diabody or ds-diabody with Ara-C enhanced the capacity of sub-populations of $\mathrm{T}$ cells to kill the tumor cells more effectively in vitro and in vivo.

\section{Results}

Co-stimulation of molecular expression on B-ALL cells

Among the 21 samples of B-ALL cells, CD80 and CD86 expression increased $100 \%$ in 10 of 21 samples following treatment with Ara-C (Table 1, patient no. 1, 4, 5, 6, $9,13,15,16,20,21)$. The samples in which CD80 or CD86 increased over $100 \%$ were chosen for the following experiments. The results are expressed as the average of the selected 10 samples.

\section{Cytotoxicity mediated by the diabody or ds-diabody in vitro}

Cytotoxic effects were enhanced along with increasing the ratio of the effector cells to the target cells. In the presence of diabody or ds-diabody, the cytotoxic effect was obviously strengthened. If the tumor cells were stimulated by pre-treatment with low doses of Ara-C before, the killing effect of activated $\mathrm{T}$ cells also increased and reached the maximum when the diabody or ds- 
Table 1 Co-stimulation of molecular expression on B-ALL cells (\%)

\begin{tabular}{llllll}
\hline Number & Patient ID & CD80 & CD80 (Ara-C) & CD86 & CD86 (Ara-C) \\
\hline 1 & 149290 & 5.48 & 12.84 & 5.20 & 12.49 \\
2 & 152618 & 4.56 & 5.30 & 5.81 & 7.21 \\
3 & 143674 & 8.71 & 9.55 & 41.77 & 59.73 \\
4 & 146937 & 2.69 & 10.30 & 10.45 & 20.39 \\
5 & 137930 & 4.98 & 13.86 & 4.37 & 31.86 \\
6 & 153776 & 4.15 & 9.55 & 4.25 & 16.41 \\
7 & 153832 & 7.21 & 7.17 & 24.05 & 27.81 \\
8 & 154438 & 2.34 & 2.75 & 1.72 & 3.11 \\
9 & 154915 & 3.94 & 8.27 & 4.32 & 15.12 \\
10 & 161080 & 0.61 & 1.04 & 3.01 & 5.12 \\
11 & 164302 & 1.02 & 1.32 & 0.31 & 0.44 \\
12 & 151732 & 0.81 & 1.32 & 16.51 & 17.55 \\
13 & 161015 & 3.73 & 33.65 & 16.02 & 47.75 \\
14 & 160483 & 9.96 & 10.86 & 2.93 & 3.45 \\
15 & 161101 & 5.27 & 5.73 & 17.53 & 43.26 \\
16 & 141322 & 5.25 & 12.90 & 6.60 & 9.07 \\
17 & 178545 & 3.01 & 4.41 & 3.97 & 6.04 \\
18 & 172540 & 9.87 & 10.1 & 11.70 & 13.66 \\
19 & 173869 & 3.68 & 3.38 & 9.48 & 11.95 \\
20 & 175981 & 4.57 & 5.65 & 0.42 & 1.65 \\
21 & 153971 & 4.48 & 17.44 & 0.44 & 24.83 \\
\hline & & & & &
\end{tabular}

diabody was added. The ds-diabody was as efficacious as the parent diabody. There was no statistical difference between the parent diabody and dsdiabody in mediating the lysis of tumor cells. Without doubt, the killing effects of CD8+ T cells were greater than $\mathrm{CD} 4+\mathrm{T}$ cells. However, CD4+ T cells contributed to the cytotoxic effects (Fig. 1).

\section{Up-regulation of activation markers by activated T cells}

The $\mathrm{T}$ cells alone or $\mathrm{T}$ cells were incubated with diabody or ds-diabody were set up as control. Expression of $\mathrm{T}$ cell activation markers CD25 and CD69 obviously increased in CD4+ or CD8+ T cells incubated with target cells and the diabody (MFI: CD4+ CD25+: $5.19 \pm 0.91$, CD4+ CD69+: $4.18 \pm 0.90$, CD8+ CD25+: $5.31 \pm 0.30$, CD8+ CD69+: $5.84 \pm 1.28)$ or ds-diabody (10 pM) (MFI: CD4+ CD25+: $5.99 \pm 1.45, \mathrm{CD} 4+\mathrm{CD} 69+: 4.89 \pm 1.55$, CD8+ CD25+: $5.97 \pm 0.47$, CD8+ CD69+: $5.56 \pm 1.06$ ). Furthermore, the $\mathrm{T}$ cell activation markers increased much more when $\mathrm{CD} 4+$ or $\mathrm{CD} 8+\mathrm{T}$ cells were incubated with the tumor cells stimulated by Ara-C than with the tumor cells itself, especially in the presence of diabody (MFI: CD4+ CD25+: $9.57 \pm 0.90$, CD4+ CD69+: $13.07 \pm$ 2.40, CD8+ CD25+: 10.14 $\pm 0.33, \mathrm{CD} 8+\mathrm{CD} 69+: 13.15 \pm$ 2.65) or ds-diabody (MFI: CD4+ CD25+: 10.54 \pm 0.95 ,
CD4+ CD69+: $14.52 \pm 1.97, \mathrm{CD} 8+\mathrm{CD} 25+: 11.09 \pm 0.39$, CD8+ CD69+: $14.11 \pm 2.59$ ) (Fig. 2).

\section{Expressions of perforin and granzyme B in the activated T cell subpopulation}

It is well known that $\mathrm{T}$ cells kill tumors by the perforin/ granzyme B pathways. We observed a greater percentage of perforin/granzyme B-expressing $\mathrm{T}$ cells after co-culturing tumors, T cells, and diabody compared to the control. Furthermore, tumor cells pre-incubated with Ara-C stimulated more perforin (MFI: CD8+: $28.24 \pm 1.18, \mathrm{CD} 4+$ : $16.77 \pm$ 1.35 ) and granzyme B (MFI: CD8+: $35.47 \pm 1.20, \mathrm{CD} 4+$ : $22.30 \pm 0.40)$ than tumor cells alone. As expected, activated CD8+ T cells expressed much more perforin/granzyme B than CD4+ T cells. The expressions of perforin/granzyme B between the diabody and ds-diabody groups had no obvious difference (Fig. 3a, b).

\section{IL2 and IL6 released by activated T cell subpopulation}

IL2 that was produced by the CD4+ T cells alone (the value was $48.7 \pm 7.3 \mathrm{pg} / \mathrm{ml}$ ) significantly increased when CD4+ T cells were incubated with tumor cells and the diabody ( $333.0 \pm 22.5 \mathrm{pg} / \mathrm{ml})$. Moreover, tumor cells stimulated by Ara-C induced CD4+ T cells to produce more IL2 $(290.6 \pm 33.5 \mathrm{pg} / \mathrm{ml})$ than tumor cells alone $(p<0.01)$. When tumor cells stimulated by Ara-C and diabody were added, IL 2 released by T cells was much more higher $(869.1 \pm 134.6 \mathrm{pg} / \mathrm{ml})$. Although CD8+ T cells released secretion of IL2, no obvious differences were observed. The result of the ds-diabody group was similar to that found with the diabody (Fig. 3c). IL6 was mainly released by CD8+ T cells (Fig. $3 \mathrm{~d}$ ). In the presence of diabody or ds-diabody, tumor cells stimulated by Ara-C induced CD8+ T cells to produce the highest amount of IL6 (diabody: $578.7 \pm 52.5 \mathrm{pg} / \mathrm{ml}$, ds-diabody: $618.8 \pm$ $31.3 \mathrm{pg} / \mathrm{ml}$ ). They are much higher than that of CD8+ T cells without combining diabody/ds-diabody (127.0 \pm $4.8 \mathrm{pg} / \mathrm{ml})$ or Ara-C $(88.57 \pm 5.3 \mathrm{pg} / \mathrm{ml})(p<0.01)$.

\section{IL3, TNFa, and IFN $\gamma$ released by activated T cell subpopulation}

The $\mathrm{T}$ cell subgroups were used as a control. CD4+ or CD8+ T cells incubated with tumor target cells and the diabody $(10 \mathrm{pM})$ released higher amounts of IL3 (CD4+ $\mathrm{T}: 388.30 \pm 44.11 \mathrm{pg} / \mathrm{ml}, \mathrm{CD} 8+\mathrm{T}: 175.85 \pm 28.37 \mathrm{pg} / \mathrm{ml})$, TNF $\alpha(C D 4+$ T: $201.32 \pm 13.22 \mathrm{pg} / \mathrm{ml}, \mathrm{CD} 8+\mathrm{T}: 732.26 \pm$ $45.90 \mathrm{pg} / \mathrm{ml})$, and IFNY (CD4+ T: $32.95 \pm 4.39 \mathrm{ng} / \mathrm{ml}$, CD8+ T: $30.85 \pm 6.49 \mathrm{ng} / \mathrm{ml})$. Also, tumor cells incubated with Ara-C stimulated $\mathrm{CD} 4+$ or $\mathrm{CD} 8+\mathrm{T}$ cells, releasing the highest IL3 $(\mathrm{CD} 4+\mathrm{T}: 1729.28 \pm 92.46 \mathrm{pg} / \mathrm{ml}$, CD8+ T: $999.39 \pm 133.09 \mathrm{pg} / \mathrm{ml}), \quad \mathrm{TNF} \alpha(\mathrm{CD} 4+\mathrm{T}$ : $613.45 \pm 28.26 \mathrm{pg} / \mathrm{ml}, \mathrm{CD} 8+\mathrm{T}$ : $1155.64 \pm 72.15 \mathrm{pg} / \mathrm{ml})$, and IFN $\gamma(\mathrm{CD} 4+\mathrm{T}: 107.60 \pm 12.69 \mathrm{ng} / \mathrm{ml}, \mathrm{CD} 8+\mathrm{T}$ : $84.21 \pm 1.23 \mathrm{ng} / \mathrm{ml}$ ) in the presence of diabody. CD4+ 

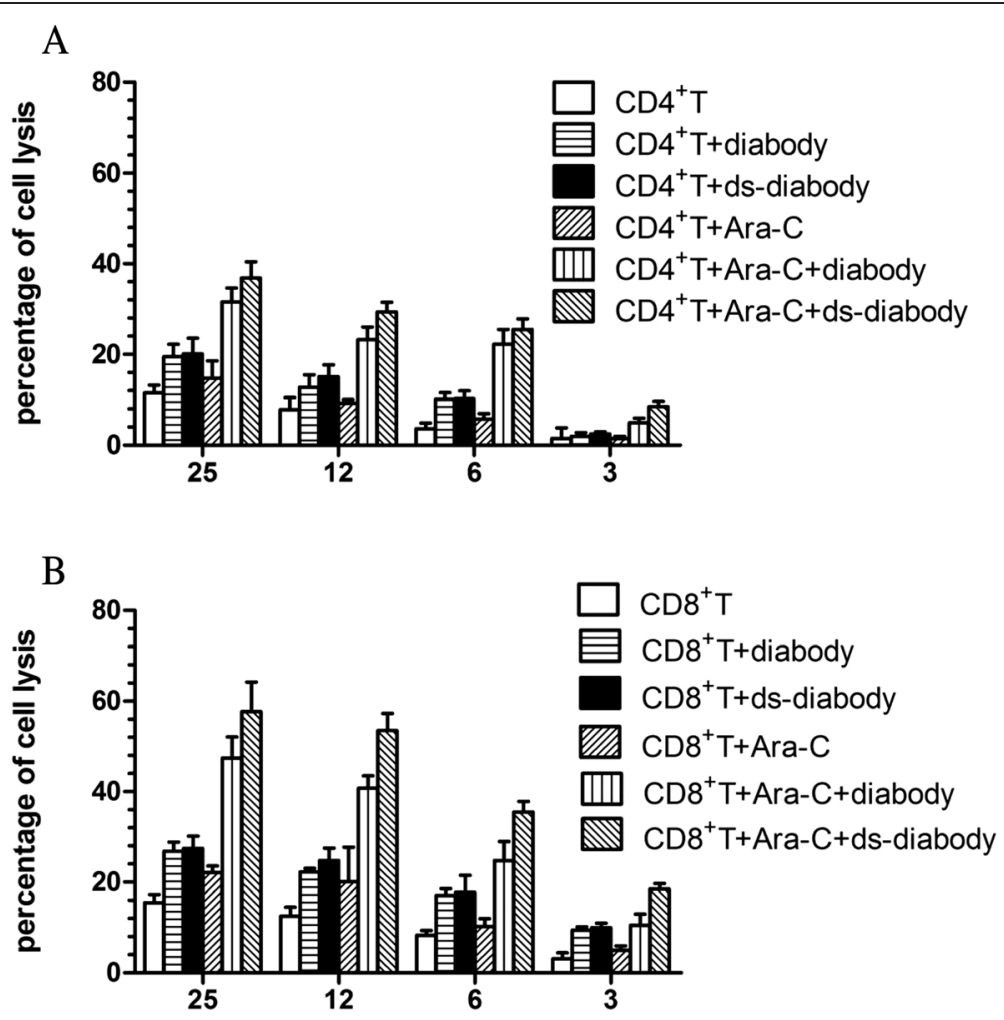

Fig. 1 Cytotoxicity of human T cell subclone in different $E / T$ ratios mediated by diabody or ds-diabody (1.0 pM) in a non-radioactive cytotoxicity assay. a Cytotoxicity of CD4+ T cells. b Cytotoxicity of CD8+ T cells. Effector-to-target cell ratio ranged from 25:1 to 3:1. The killing effect of activated $\mathrm{CD} 4+$ or $\mathrm{CD} 8+\mathrm{T}$ cells reached the maximum when Ara-C $(0.25 \mu \mathrm{M})$ and the diabody or ds-diabody were both added. There was no statistical difference between the parent diabody and ds-diabody in mediating the lysis of tumor cells. The killing effect of CD8+ T cells was greater than that of CD4+ T cells. Data shown are the means \pm SD of experiments for each B-ALL sample cells performed in quadruplicate

$\mathrm{T}$ cells released more IL3 than CD8+ T cells, while CD8+ $\mathrm{T}$ cells produced more TNF $\alpha$. IFN $\gamma$ had no difference when released by both $\mathrm{T}$ cell subgroups. Ds-diabody also mediated the CD4+ or CD8+ T cells to release as many of these cytokines as diabody (Fig. 4b,d,f). The results of qPCR were correspondence to ELISA(Fig.4a,c,e).

\section{Tumor growth inhibition in vivo}

The antitumor activity of the diabody or ds-diabody with or without Ara-C and that of the control groups is shown in Table 2. Five B-ALL sample cells were successfully established in the tumor engraftment models on NOD/SCID mice. No obvious tumor-inhibiting effect was observed in the mice treated with $\mathrm{T}$ cells, diabody, ds-diabody, or Ara-C alone. Also, $\mathrm{T}$ cells combined with Ara-C did not display apparent antitumor activity. The mice treated by $\mathrm{T}$ cells and diabody or dsdiabody $(p<0.05)$ showed obvious antitumor activity. Furthermore, when Ara-C was added, the tumor inhibition of the combination was more significant than that of the other groups $(p<0.01)$.

\section{Discussion}

Traditional chemotherapy disrupts fundamental regulatory pathways essential for tumor cell growth and survival. Meanwhile, they usually cause severe toxicity to normal tissues and induce drug resistance. Many standard and high-dose chemotherapy regimens are immunosuppressive, contributing to leukopenia and lymphopenia [35]. However, an abundance of evidence suggests that low-dose chemotherapy may augment tumor immunity via a variety of pathways. The critical pathway is one in which chemotherapy can adjust the tumor microenvironment by modulating the expression of tumor antigens, accessory molecules of $\mathrm{T}$ cell activation or inhibition, and molecules involved in antigen processing and presentation [36].

In the previous study, we found that Ara-C upregulated CD80 expressed on CD19+ human leukemia cell-line Nalm- 6 and some specimens of B-ALL patientderived cells. The CD80-CD28 signaling pathway was the most potent co-stimulatory pathway facilitating antigen-specific $\mathrm{T}$ cell activation. Here, we found that CD80 and CD86 expression increased nearly $100 \%$ on $50 \%$ of B-ALL samples after being treated with Ara-C. 


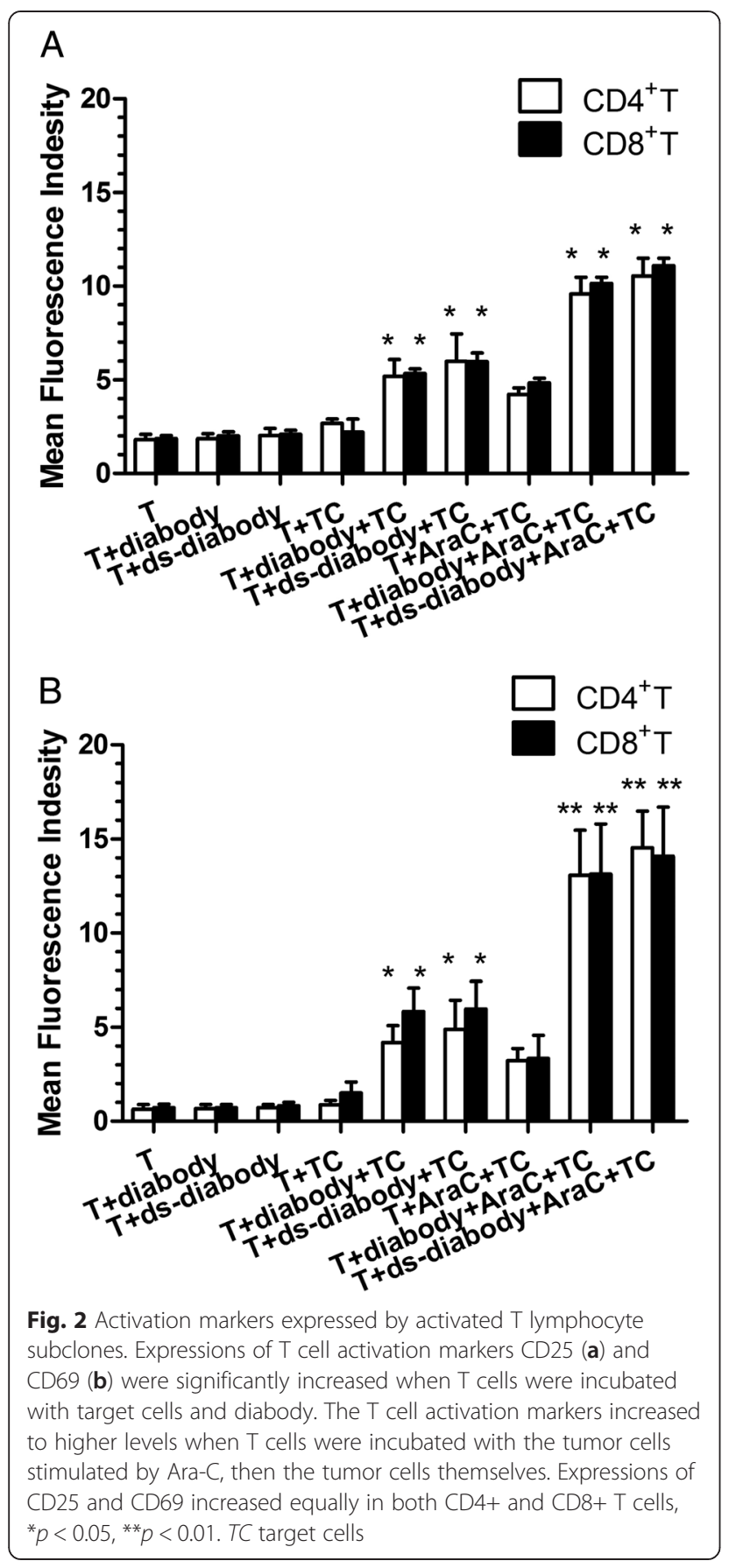

An assay of human acute myelocytic leukemia (AML) cells demonstrated that exposure to doses of Ara-C as low as $0.05 \mathrm{mM}$ led to a marked increase of CD86 and a lesser increase of CD80 [37]. Most specimens showed enhanced expressions of CD80 or CD86, but some subtypes of AML, especially FAB M0 and M1, showed no modification or a decrease of expression. Thus, different drugs may stimulate different subtypes of malignant cells through a variety of signaling pathways.
Peripheral CTLs with specificity against leukemic antigens found in chronic myeloid leukemia (CML) patients and healthy individuals indicated that a natural anti-leukemic immune response might exist in vivo [38, 39]. Additionally, mouse leukemic cells exposed in vivo to Ara-C were more susceptible to CTL-mediated cell killing [36]. This result suggested that the specific anti-leukemic activity of CTL, acting in synergy with enhanced sensitivity of leukemic cells to immune-mediated cell killing induced by chemotherapy, might eradicate minimal residual disease [40]. According to our previous study, cytotoxicity would be enhanced if CTL were recruited around the tumor cells. Furthermore, in the presence of B-ALL samples, both CD8+ and CD4+ T cells were potently activated. Expression of CD25 and CD69 was up-regulated equally in CD4+ T cells and CD8+ T cells. However, CD8+ $\mathrm{T}$ cells made the major contribution to redirect target cell lysis by functional expression of granzyme $\mathrm{B}$ and perforin. CD4+ T cells also participated in the perforin/granzyme pathway to lyse the target cells. However, CD4+ T cells played a main role in modulating other immunocyte functions including CD8+ T cells by releasing IL2. Previous studies have indicated that the cytokine secretion profile differs between CD4+ and CD8+ cells. The CD8+ cells have been shown to secrete Th1 cytokines, whereas CD4+ cells secrete both Th1 and Th2 cytokines [41]. Originally, it was suggested that a Th1-type response leads to tumor regression, whereas Th2 cytokines down-regulate antitumor immunity [42]. In normal conditions, Th1 and Th2 cytokines secreted by immunocytes modulate the balance of immunological response to tumor growth. Thus, we speculated that in the tumor microenvironment around the target cells in vivo, diabody or dsdiabody and Ara-C would enhance antitumor response and impair immunosuppression.

The use of bi-specific antibodies essentially leads to strong $\mathrm{T}$ cell activation; in the meantime, they also induce the $\mathrm{T}$ cells to produce plenty of proinflammatory cytokines [43], such therapies might also trigger tumor cells to employ immunosuppressive strategies to escape antibody-mediated tumor cell lysis. Moreover, reduced T cell activation and impaired tumor cell lysis were observed in some patient samples [44, 45]. As a consequence of bi-specific antibody-mediated $\mathrm{T}$ cell activation in this paper, IL3, TNF $\alpha$, and IFN $\gamma$ were released into cell culture supernatants either by $\mathrm{CD} 4+$ or $\mathrm{CD} 8+\mathrm{T}$ cells. Among them, IL3 was identified among the most important cytokines for regulating mast cell growth and the differentiation, migration, and effector function activities of many hematopoietic cells [46]. It is predominantly produced by activated T cells, natural killer (NK) cells, and mast cells. IL3 causes severe hypersensitivity 


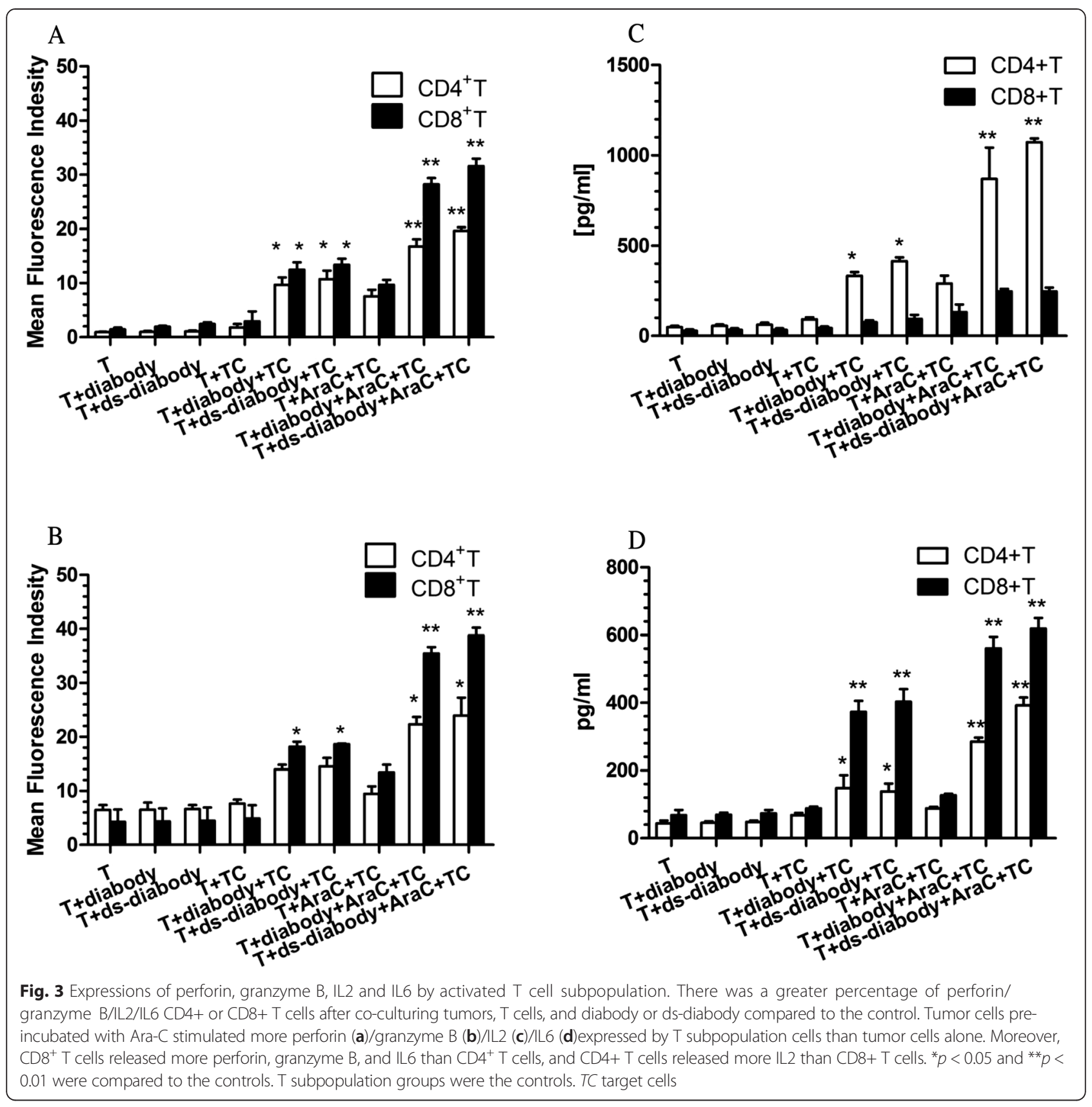

reactions and plays a pivotal role in exacerbating inflammatory responses in vivo. This also might help overcome the immunosuppressive tumor milieu and reactivate pre-existing, tumor-specific $\mathrm{T}$ lymphocytes within the scope of an antigen-specific immunotherapy.

The most common side effect associated with the bispecific immunotherapy is cytokine release syndrome (CRS), an inflammatory symptom resulting from cytokine elevations associated with $\mathrm{T}$ cell engagement and proliferation [47]. The most significantly elevated cytokines in the CRS are IL10, IL6, and IFNY [48]. IL6 is one of the most important cytokines involved in CRS. We measured cytokine IL6 by ELISA. The quantity of IL6 released in the supernatant is much lower than other cytokines. We just measure it in vitro with limited time of incubation. However, we did not measure IL6 in vivo, but the mice during the period of treatment have no obvious abnormal behaviors as anorexia, weight loss, allergy, and so on. So, the exact quantity of release of IL6 associated with T cell engagement by diabody in vivo needs to be confirmed in the future.

$\mathrm{T}$ cell activation and dysfunction relies on direct and modulated receptors. Based on their functional outcome, 


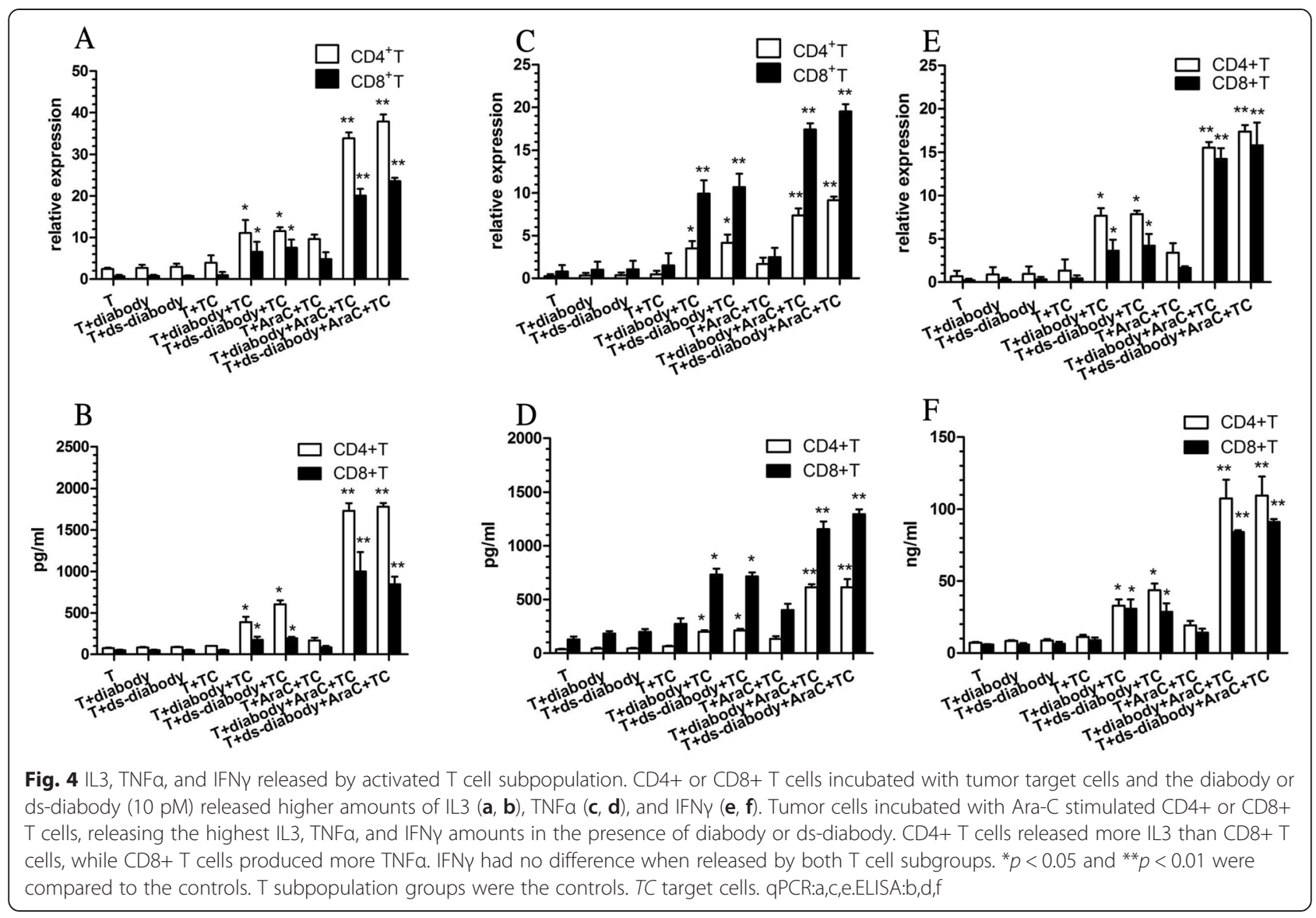

co-signaling molecules can be divided as co-stimulators and co-inhibitors, which positively and negatively control the priming, growth, differentiation, and functional maturation of a $\mathrm{T}$ cell response. The co-inhibitory molecules on $\mathrm{T}$ cell surface are CTLA-4, PD-1, LAG-3, CD160, and TIM-3 [49]. Recently, target immunotherapy using PD-1 and PD-L1 monoclonal antibodies (MoAbs) was demonstrated to significantly induce durable tumor regression and prolong disease stabilization in patients with selected advanced cancers [50]. Krupka et al. indicated that the CD33/CD3 BiTE antibody construct AMG 330 on primary acute myeloid leukemia (AML) cell AMG 330 up-regulates immune checkpoints, PD-1 and PD-L1 on target and effector cells [43]. PD-L1 was strongly up-regulated on primary AML cells upon AMG 330 addition to ex vivo cultures. Through blockade of the PD-1/PD-L1 interaction, AMG 330-mediated lysis, $\mathrm{T}$ cell proliferation, and IFNY secretion were significantly enhanced. Another way of engaging $\mathrm{T}$ cells is chimeric antigen receptor-modified $\mathrm{T}$ cells (CART). CART uses adoptive transfer of $\mathrm{T}$ lymphocytes engineered to express a single-chain fragment variable region $(\mathrm{scFv})$ domain linked to the signaling domain of the $\mathrm{T}$ cell receptor (TCR) [51], plus various costimulatory domains. Urbanska et al. combined the application of
frBsAbs specific for CD20 or HER2 with T cells that are genetically engineered to express a unique BsAb-binding immune receptor (BsAb-IR) [52]. The lytic activity of primary human $\mathrm{T}$ cells expressing the BsAb-IR was specifically redirected against CD20+ leukemic cells or HER2+ epithelial cancer cells. This approach has the unique advantage to simultaneously and locally activate selected population of gene-engineered $\mathrm{T}$ cells and trigger the co-stimulatory signals by application of one single bi-specific molecule.

In regards to tumor growth inhibition in vivo, the efficacy of growth inhibition by ds-diabody was much greater than that of its diabody counterpart, although their activity in vitro in cultured cells was similar. This improved antitumor effect in vivo was mainly due to the improved stability of the diabody. The results coincided with those from the previous experiment. So, the dsdiabody was not only useful for malignant cell-lines but also valuable for clinical trials.

In this study, we found that at low doses, Ara-C upregulated the expressions of CD80, CD86, or both over $100 \%$ in nearly $50 \%$ of specimens of B-ALL patientderived cells. A combination of diabody or ds-diabody with low-dose Ara-C induced $\mathrm{T}$ lymphocytes to exhibit greater cytotoxicity in those B-ALL cells in vitro and in 
Table 2 Tumor growth in vivo (\%)

\begin{tabular}{|c|c|c|c|c|c|c|c|c|c|c|c|c|}
\hline & \multicolumn{2}{|l|}{ Patient 1} & \multicolumn{2}{|l|}{ Patient 2} & \multicolumn{2}{|l|}{ Patient 3} & \multicolumn{2}{|l|}{ Patient 4} & \multicolumn{2}{|l|}{ Patient 5} & \multicolumn{2}{|l|}{ Average } \\
\hline & $\mathrm{CD} 45+$ & CD19+ & CD45+ & CD19+ & CD45+ & CD19+ & CD45+ & CD19+ & $\mathrm{CD} 45+$ & CD19+ & CD45+ & CD19+ \\
\hline$\overline{\mathrm{PBS}}$ & $87.8 \pm 6.8$ & $87.6 \pm 9.9$ & $83.5 \pm 7.3$ & $83.9 \pm 8.9$ & $79.2 \pm 9.2$ & $79.6 \pm 6.7$ & $85.1 \pm 6.1$ & $85.7 \pm 8.3$ & $88.3 \pm 8.1$ & $88.5 \pm 10.4$ & $84.8 \pm 5.6$ & $85.1 \pm 5.5$ \\
\hline $\mathrm{T}$ & $82.1 \pm 5.9$ & $82.8 \pm 6.1$ & $80.1 \pm 9.4$ & $80.6 \pm 5.4$ & $78.2 \pm 7.1$ & $78.9 \pm 7.8$ & $81.2 \pm 5.9$ & $81.0 \pm 7.9$ & $80.9 \pm 10.9$ & $81.2 \pm 7.8$ & $80.5 \pm 2.3$ & $80.9 \pm 2.0$ \\
\hline$T+$ diabody & $60.0 \pm 7.2$ & $59.8 \pm 5.7$ & $60.1 \pm 1.6$ & $59.5 \pm 5.6$ & $58.8 \pm 6.1$ & $58.5 \pm 6.5$ & $62.5 \pm 2.6$ & $61.9 \pm 6.4$ & $62.6 \pm 5.7$ & $63.0 \pm 3.4$ & $60.8 \pm 2.0^{*}$ & $60.5 \pm 2.0^{*}$ \\
\hline$T+d s-d i a b o d y$ & $49.5 \pm 5.5$ & $48.7 \pm 6.2$ & $47.6 \pm 3.2$ & $48.1 \pm 7.1$ & $46.3 \pm 4.6$ & $46.0 \pm 5.7$ & $49.1 \pm 4.3$ & $49.7 \pm 5.1$ & $50.4 \pm 7.2$ & $50.7 \pm 2.7$ & $48.6 \pm 2.3^{*}$ & $48.6 \pm 2.6^{*}$ \\
\hline $\mathrm{T}+\mathrm{Ara}-\mathrm{C}$ & $77.0 \pm 8.1$ & $77.8 \pm 7.4$ & $67.3 \pm 3.3$ & $68.0 \pm 4.6$ & $70.1 \pm 5.6$ & $69.9 \pm 6.9$ & $72.0 \pm 6.8$ & $70.8 \pm 3.8$ & $75.1 \pm 5.3$ & $75.5 \pm 5.5$ & $72.3 \pm 5.0$ & $72.4 \pm 2.5$ \\
\hline $\mathrm{T}+$ Ara-C + diabody & $21.5 \pm 3.2$ & $20.8 \pm 2.8$ & $15.8 \pm 3.1$ & $15.0 \pm 3.3$ & $14.3 \pm 2.7$ & $13.9 \pm 3.7$ & $19.7 \pm 2.1$ & $19.1 \pm 0.9$ & $17.8 \pm 1.1$ & $17.9 \pm 2.7$ & $17.8 \pm 3.5^{* *}$ & $17.3 \pm 3.4^{* *}$ \\
\hline $\mathrm{T}+$ Ara-C + ds-diabody & $1.3 \pm 0.5$ & $1.2 \pm 0.4$ & $0.8 \pm 0.2$ & $0.7 \pm 0.1$ & $0.7 \pm 0.2$ & $0.5 \pm 0.1$ & $2.5 \pm 0.3$ & $2.4 \pm 0.4$ & $2.0 \pm 1.2$ & $2.1 \pm 0.5$ & $1.5 \pm 0.8^{* *}$ & $1.4 \pm 0.9^{* *}$ \\
\hline
\end{tabular}


vivo. Furthermore, in vivo, the ds-diabody was more efficient than its parent diabody at inducing tumor cell lysis due to its greater stability. Altogether, our findings illustrated the advantage of combining immunotherapy with chemotherapy in preclinical tumor models, which has set the foundation for developing new clinical strategies aimed at targeting leukemia and lymphoma.

\section{Conclusion}

The therapy of $\mathrm{T}$ cells that was induced by diabody or ds-diabody combined with low dose of Ara-C was not only useful for malignant cell-lines but also valuable for clinical trials. In vivo, the ds-diabody was more efficient than its parent diabody due to its greater stability.

\section{Methods}

\section{Samples and bi-specific antibody}

B-ALL cells were obtained from 21 newly diagnosed patients after their informed consent and with the approval of the Clinical Research Ethics Board of the Institute of Hematology, Chinese Academy of Medical Sciences (Tianjin, China). Diagnosis and classification of B-ALL cells were based on the criteria of the FAB group. Cells were maintained in RPMI 1640 (Gibco, Grand Island, NY, USA) containing $10 \%$ fetal bovine serum (FBS) and grown at $37{ }^{\circ} \mathrm{C}$ with $5 \% \mathrm{CO}_{2}$. Bi-specific anti-CD3 $\times$ anti-CD19 diabody and its disulfide-stabilized format (ds-diabody) constructed previously are stored in our lab [31].

\section{Isolation of PBMC and sorting T lymphocytes}

With informed consent, blood samples were collected from healthy volunteers, and peripheral blood mononuclear cells (PBMCs) were isolated by Ficoll-Hypaque density-gradient centrifugation. The interphase cells were washed twice, counted, and tested for viability with trypan blue dye. Then, their monocytes were depleted by adherence to plastic flasks for $2 \mathrm{~h}$. Non-adherent cells were used for $\mathrm{T}$ cell isolation using fluorescenceactivated cell sorting (FACS). For the sorting of $\mathrm{T}$ cells, $1 \times 10^{8}$ PBMC in $1 \mathrm{ml}$ phosphate-buffered saline (PBS) was incubated with $15 \mu \mathrm{l}$ of allophycocyanin (APC)-conjugated anti-human CD2 mAbs (clone RPA-2.10, BD Pharmingen, San Diego, CA, USA), anti-human CD4 mAbs, and anti-human CD8 mAbs mixture at $4{ }^{\circ} \mathrm{C}$ for $60 \mathrm{~min}$. After washing twice with PBS, $\mathrm{T}$ lymphocytes were sorted using FACS (FACS Aria II Becton, Dickinson and Co., Franklin Lakes, NJ, USA), and the collected cells were cultured in complete RPMI-1640 medium (10\% FBS) supplemented with $50 \mathrm{IU} / \mathrm{ml}$ of IL2 for $48 \mathrm{~h}$.

\section{Co-stimulation molecule expression on B-ALL cells}

B-ALL at $1 \times 10^{6}$ cells $/ \mathrm{ml}$ were incubated with Ara-C at the concentration of $0.25 \mu \mathrm{M}$ for $72 \mathrm{~h}$. After being washed in PBS twice, the cells were incubated with FITC-conjugated anti-human CD80 mAb (clone L307.4, BD Biosciences, San Jose, CA, USA) and PE-conjugated anti-human CD86 antibody mAb (clone IT2.2, BD Biosciences, San Jose, CA, USA) for $1 \mathrm{~h}$ at $4{ }^{\circ} \mathrm{C}$. The stained cells were then analyzed using flow cytometry. The assay was repeated three times for each condition. The B-ALL sample cell-expressed CD80 or CD86 increasing over $100 \%$ were chosen for the following experiments.

\section{Cytotoxicity test in vitro}

Cytolytic activity of $\mathrm{T}$ lymphocytes targeted by the diabody and ds-diabody was determined using the calceinrelease assay. The $\mathrm{T}$ lymphocytes are from one single healthy volunteer. The B-ALL cells stimulated by Ara-C at concentrations of $0.25 \mu \mathrm{M}$ for $72 \mathrm{~h}$ or not were prepared as target cells. For the experiments, quadruplicates of $1 \times 10^{5}$ labeled target cells and CD4+ or CD8+ T cells at different E:T cell ratios ranging from 25:1 to 3:1 per well were added to the round-bottom 96-well plates in a final volume of $100 \mu$ l. Diabody and ds-diabody dilutions of $1.0 \mathrm{pM}$ were added to the final volume for the assays. The plates were centrifuged at $250 \times \mathrm{g}$ for $4 \mathrm{~min}$ and incubated for $4 \mathrm{~h}$ in a humidified incubator at $37{ }^{\circ} \mathrm{C}$ in $5 \% \mathrm{CO}_{2}$. After incubation, the cells were concentrated by centrifugation, and the supernatant was transferred to a new 96-well plate. Calcein fluorescence in the supernatant was determined using a fluorescence plate reader (Fluoroskan Ascent FL, Thermo-Fisher, USA; excitation at $485 \mathrm{~nm}$, emission at $535 \mathrm{~nm}$ ). The percentage of cytotoxicity was calculated using this formula:

$$
\begin{aligned}
& \left(\mathrm{F}_{\text {experimental lysis }}-\mathrm{F}_{\text {spontaneous release }}\right) \\
& /\left(\mathrm{F}_{\text {maximal lysis }}-\mathrm{F}_{\text {spontaneous release }}\right) \times 100 .
\end{aligned}
$$

Maximal lysis values were obtained by adding $2 \%$ Triton X-100 to labeled target cells. Spontaneous release was observed only in the labeled target cells without $\mathrm{T}$ cells and antibodies. Each sample cell assay was repeated four times for each condition.

\section{Up-regulation of $\mathrm{T}$ cell activation markers}

To determine the CD4+ or CD8+ T cell surface activation markers, PE-conjugated anti-human CD25 mAb (clone 2A3, BD Biosciences, San Jose, CA, USA) and FITC-conjugated anti-human CD69 mAb (clone L78, BD Biosciences, San Jose, CA, USA) were used as an antibody mixture. Experimental groups were constructed according to a cytotoxicity test in vitro. The ratio of $\mathrm{T}$ cells to target cells was $25: 1$, and the concentration of the diabody or ds-diabody was $1.0 \mathrm{pM}$. The B-ALL cells that were incubated with Ara-C at concentrations of $0.25 \mu \mathrm{M}$ for $72 \mathrm{~h}$ or not were prepared as target cells. After incubation with the target cells for $4 \mathrm{~h}$, the 
lymphocytes were collected and washed in PBS with $3 \%$ FBS and $0.1 \% \mathrm{NaN}_{3}$. Then, $50 \mu \mathrm{l}$ of the antibody mixture was added, and the cells were incubated for $1 \mathrm{~h}$ at $4{ }^{\circ} \mathrm{C}$. The cells were washed, and the pellets were resuspended in $600 \mu \mathrm{l}$ of PBS. Samples were analyzed using flow cytometry. The $\mathrm{T}$ cells alone and $\mathrm{T}$ cells incubating with diabody or ds-diabody without target cells were set up as control.

\section{Expressions of perforin and granzyme B in activated T cell subpopulation}

The ratio of CD4+ or CD8+ T cells to target cells was $25: 1$, and the concentration of the diabody or ds-diabody was $1.0 \mathrm{pM}$. The B-ALL cells that were incubated with Ara-C at concentrations of $0.25 \mu \mathrm{M}$ for $72 \mathrm{~h}$ or not were prepared as target cells. Experimental groups were constructed according to a cytotoxicity test in vitro. The cells were washed twice in PBS supplemented with $2 \%$ bovine serum albumin (BSA) and resuspended in $100 \mu \mathrm{l}$ of fixative (FixPerm kit, Caltag) at room temperature (RT) for $15 \mathrm{~min}$. After further washing, the cell pellet was resuspended in $100 \mu \mathrm{l}$ of permeabilization solution (FixPerm kit, Caltag) for $15 \mathrm{~min}$ at RT and then incubated with a FITC-conjugated anti-perforin mAb (cloned 8G9, BD Pharmingen) and PE-conjugated anti-granzyme B mAb (cloned CB9, BD Pharmingen) mixture for $45 \mathrm{~min}$ at $4{ }^{\circ} \mathrm{C}$. The cells were then washed twice in PBS-BSA and analyzed by flow cytometry. The T cells alone and $\mathrm{T}$ cells incubating with diabody or ds-diabody without target cells were set up as control

\section{IL2 and IL6 release}

IL2 or IL6 concentrations were analyzed in the supernatants of activated CD4+ or CD8+ T cells using a human IL2 or IL6 ELISA kit (NeoBioscience, Shenzhen, China). Experimental groups were constructed according to a cytotoxicity test in vitro. Cytokines released by $\mathrm{T}$ cells alone and $\mathrm{T}$ cells incubating with diabody or ds-diabody served as control. Approximately $1 \times 10^{6} \mathrm{~T}$ cells were co-cultured with $4 \times 10^{4}$ target cells. After incubation with the target cells for $4 \mathrm{~h}$, supernatant was removed and analyzed according to the manufacturer's protocol. The measurements were performed on an ELISA plate reader (Thermo Fisher Scientific, Waltham, MA, USA).

\section{Release of IL3, TNFa, and IFN $\gamma$ by activated T cell subpopulation}

The ratio of CD4+ or CD8+ $\mathrm{T}$ cells to target cells was $25: 1$, and the concentration of the diabody or ds-diabody was $1.0 \mathrm{pM}$. T The B-ALL cells that were incubated with Ara-C at concentrations of $0.25 \mu \mathrm{M}$ for $72 \mathrm{~h}$ or not were prepared as target cells. Experimental groups were constructed according to a cytotoxicity test in vitro. RNA isolation, DNase treatment, and RT-Total RNA were isolated using TRIzol (Invitrogen), treated with DNase I (Invitrogen), and then $2 \mu \mathrm{g}$ RNA were reversetranscribed using Superscript II RT (Invitrogen) following the manufacturer's instructions in a total volume of $20 \mu$ l. Primers for real-time PCR for IL3, TNF $\alpha$, and IFN $\gamma$ genes and the housekeeping gene GAPDH were designed using Primer Premier Software 5.0. Human GAPDH primers were 5'-GAAGGTGAAGGTCGGA GT-3' (forward) and 5'-GAAGATGGTGATGGGATT TC-3' (reverse). IL3 primers were $5^{\prime}$-GGTTAGCACT GTCTCCAGATCG-3' (forward) and 5' -TTCTTGCCA GCTCTACCACC-3' (reverse). IFN $\gamma$ primers were $5^{\prime}$ GGCTGTTTCTGGCTGTTACTGC-3' (forward) and 5' -ACTCCTTTTCCGCTTCCTGAGG-3' (reverse). TNF $\alpha$ primers were 5'-ATGAGCACAGAAAGCATGATCC-3' (forward) and 5'-ACAAGCAGGAATGAGAAGAGG-3' (reverse). Real-time PCR was performed with a QuantiTect SYBR Green PCR kit (Takara) on the ABI Prism 7500 Fast Sequence Detection System. Thermal cycling conditions were $95{ }^{\circ} \mathrm{C}$ for $15 \mathrm{~s}$, followed by 40 cycles of $5 \mathrm{~s}$ at $95{ }^{\circ} \mathrm{C}$ and $40 \mathrm{~s}$ at $60{ }^{\circ} \mathrm{C}$. PCR reactions were performed in a total volume of $20 \mu \mathrm{l}$ containing $2 \mu \mathrm{l}$ of sample cDNA and $0.2 \mu \mathrm{M}$ of each primer, and the SYBR Green PCR kit was used following manufacturer's instructions. Each test was amplified in three different wells. The relative quantification of gene expression was assessed by $2^{-\Delta \Delta \mathrm{Ct}}, \Delta \Delta \mathrm{Ct}=\Delta \mathrm{Ct}$ sample $-\Delta \mathrm{Ct}$ control. Gene expression was assessed by the ratio of the expression level in each patient sample against the mean expression in all normal samples. Also, the quantity of cytokines IL3, TNF $\alpha$, and IFN $\gamma$ released into the supernatant by activated $\mathrm{T}$ cell subpopulation were measured by ELISA (NeoBioscience, Shenzhen, China) and analyzed according to the manufacturer's protocol. The T cells alone and $\mathrm{T}$ cells incubating with diabody or dsdiabody without target cells were set up as control.

\section{Tumor growth inhibition in vivo}

NOD/SCID mice (Cancer Institute, Chinese Academy of Medical Sciences, Beijing, China) were kept under sterile conditions and received autoclaved food, water, and bedding. Mice that were 6-8 weeks old received 400 cGy from ${ }^{137} \mathrm{Cs}$ source $24 \mathrm{~h}$ before injection of B-ALL cells. Then, $1 \times 10^{7} \mathrm{~B}$-ALL cells were injected into each mouse via the tail vein. Cohorts of six mice were injected with cells from the same B-ALL sample, subjected to the same experimental conditions, and analyzed in parallel. Values shown for engraftment of B-ALL cells in mouse $\mathrm{BM}$ are the mean values obtained for all mice that received the same treatment and survived to the time of analysis. Six days after tumor inoculation, each mouse in the same B-ALL sample group was treated with preactivated $\mathrm{T}$ cells $\left(5 \times 10^{6}\right.$ cells/mouse $)$, T cells combined with diabody (2.0 nM/mouse), T cells combined with ds- 
diabody ( $2.0 \mathrm{nM} /$ mouse), $\mathrm{T}$ cells combined with Ara-C $(1 \mathrm{mg} / \mathrm{kg}), \mathrm{T}$ cells combined with Ara-C and diabody, and $\mathrm{T}$ cells combined with Ara-C and ds-diabody via the tail vein. The treatments were administered every 7 days for 3 weeks. Eight weeks after the last treatment, the mice were killed by $\mathrm{CO}_{2}$ inhalation, and $\mathrm{BM}$ was obtained from the four long bones by flushing with Alpha MEM with 50 \% FCS. Cells from mouse tissue were prepared for FACS analysis as described previously [53]. Half the cells were then incubated for $30 \mathrm{~min}$ on ice with a mouse IgG1 isotype control (Becton Dickinson Immunocytometry Systems, San Jose, CA, USA), and the other half were incubated with APC mouse antihuman CD45 ( BD Pharmingen; Mouse IgG1, $\mathrm{K}$ ) and PE mouse anti-human CD19 ( BD Pharmingen; Mouse IgG1, $\mathrm{k}$ ) to detect human cells. Cells were washed and stained with $2 \mu \mathrm{g} / \mathrm{ml}$ propidium iodide. FACS analysis was performed using FACS Aria II. The percentage of $\mathrm{CD} 45^{+}$and $\mathrm{CD} 19^{+}$cells was determined after excluding $99.9 \%$ of cells labeled with the isotype control and nonviable cells. Nonspecific binding of CD45 on mouse BM cells was reliably $\leq 0.1 \%$.

\section{Statistical analysis}

All data were expressed as mean \pm standard deviation and statistically analyzed by the Student's $t$ test with SPSS version 18.0 statistical analysis software (IBM, Armonk, NY, USA).

\begin{abstract}
Abbreviations
APC: Allophycocyanin; Ara-C: Cytarabine; B-ALL: B-acute lymphoblastic leukemia; BiTE: Bi-specific T cell engager; bsAbs: Bi-specific antibodies; CART: Chimeric antigen receptor-modified T cells; CRS: Cytokine release syndrome; ds-diabody: Disulfide-stabilized format; FACS: Fluorescenceactivated cell sorting; PBMCs: Peripheral blood mononuclear cells; TAA: Tumor-associated antigen.
\end{abstract}

\section{Competing interests}

The authors declare that they have no competing interests.

\section{Authors' contributions}

DF contributed to the cytotoxicity assay in vitro and in vivo, and the joint first authors WL constructed the plasmids of anti-CD3Fv- $\Delta \mathrm{IL} 3$ and ds-antiCD3Fv- $\Delta \mathrm{IL} 3$ and completed the expression and purification of these two fusion proteins. YY isolated T lymphocytes from PBMC. XZ finished the binding assay of the fusion proteins. $Y Y$ contributed to the stability assay in vitro. MY,JW and DX were the corresponding authors and contributed to the design of this subject. All authors read and approved the final manuscript.

\section{Acknowledgements}

This work was supported by grants from the Natural Science Foundation of China (Grant Nos. 30873091 and 30971291), Natural Science Foundation of Tianjin (Grant No. 05YFGZGX02800), and National Science and Technology Major Project (Grant No. 2009ZX09103-720).

\footnotetext{
Author details

${ }^{1}$ State Key Laboratory of Experimental Hematology, Institute of Hematology and Hospital of Blood Diseases, Chinese Academy of Medical Sciences and Peking Union Medical College, Tianjin 300020, People's Republic of China. ${ }^{2}$ Department of Maxillofacial and E.N.T. Oncology, Tianjin Medical University Cancer Institute and Hospital, National Clinical Research Center of Cancer,
}

Key Laboratory of Cancer Prevention and Therapy, Tianjin 300060, People's Republic of China. ${ }^{3}$ School of Pharmacy, Tianjin Medical University, Tianjin 300070, People's Republic of China.

Received: 6 July 2015 Accepted: 28 September 2015

Published online: 06 October 2015

\section{References}

1. Geethakumari PR, Hoffmann MS, Pemmaraju N, Hu S, Jorgensen JL, O'Brien $\mathrm{S}$, et al. Extramedullary B lymphoblastic leukemia/lymphoma (B-ALL/B-LBL): a diagnostic challenge. Clin Lymphoma Myeloma Leuk. 2014;14:e115-8.

2. Wiegering $V$, Frank J, Freudenberg $S$, Morbach $H$, Schlegel PG, Eyrich M, et al. Impaired B-cell reconstitution in children after chemotherapy for standard or medium risk acute precursor B-lymphoblastic leukemia. Leuk Lymphoma. 2014;55:870-5.

3. Boonchalermvichian C, Xie Y, Brynes RK, Siddiqi IN. Spontaneous, transient regression of $B$ lymphoblastic leukemia in an adult patient: a variant presentation of prodromal/pre-ALL. Leuk Res. 2012;36:e57-9.

4. Faderl S, O'Brien S, Pui CH, Stock W, Wetzler M, Hoelzer D, et al. The biology and therapy of adult acute lymphoblastic leukemia. Cancer. 2010;116:1165-76.

5. Mellman I, Coukos G, Dranoff G. Cancer immunotherapy comes of age. Nature. 2011:480:480-9.

6. Akinleye A, Furqan M, Mukhi N, Ravella P, Liu D. MEK and the inhibitors: from bench to bedside. J Hematol Oncol. 2013;6(1):27.

7. Furqan M, Akinleye A, Mukhi N, Mittal V, Chen Y, Liu D. STAT inhibitors for cancer therapy. J Hematol Oncol. 2013;6(1):90.

8. Zhao $Y$, Huang H, Wei G. Novel agents and biomarkers for acute lymphoid leukemia. J Hematol Oncol. 2013;6:40.

9. Grover NS, Park SI.Novel Targeted Agents in Hodgkin and Non-Hodgkin Lymphoma Therapy.Pharmaceuticals (Basel). 2015;8:607-36.

10. Suresh T, Lee L, Joshi J, Barta S. New antibody approaches to lymphoma therapy. J Hematol Oncol. 2014;7(1):58.

11. Mellor JD, Brown MP, Irving HR, Zalcberg JR, Dobrovic A. A critical review of the role of Fc gamma receptor polymorphisms in the response to monoclonal antibodies in cancer. J Hematol Oncol. 2013;6:1.

12. Hoelzer D, Gokbuget N. Chemoimmunotherapy in acute lymphoblastic leukemia. Blood Rev. 2012;26:25-32.

13. Kantarjian H, Thomas D, Wayne AS, O'Brien S. Monoclonal antibody-based therapies: a new dawn in the treatment of acute lymphoblastic leukemia. J Clin Oncol. 2012;30:3876-83.

14. Thomas DA, O'Brien S, Faderl S, Garcia-Manero G, Ferrajoli A, Wierda W, et al. Chemoimmunotherapy with a modified hyper-CVAD and rituximab regimen improves outcome in de novo Philadelphia chromosome-negative precursor B-lineage acute lymphoblastic leukemia. J Clin Oncol. 2010;28:3880-9.

15. Hoelzer D. Targeted therapy with monoclonal antibodies in acute lymphoblastic leukemia. Curr Opin Oncol. 2013;25:701-6.

16. Breton CS, Nahimana A, Aubry D, Macoin J, Moretti $P$, Bertschinger M, et al. A novel anti-CD19 monoclonal antibody (GBR 401) with high killing activity against B cell malignancies. J Hematol Oncol. 2014;7:33.

17. Akinleye A, Chen Y, Mukhi N, Song Y, Liu D. Ibrutinib and novel BTK inhibitors in clinical development. J Hematol Oncol. 2013;6(1):59.

18. Han E, Li X-I, Wang C-r, Li T-f, Han S-y. Chimeric antigen receptorengineered $T$ cells for cancer immunotherapy: progress and challenges. J Hematol Oncol. 2013;6(1):47.

19. Wu J, Fu J, Zhang M, Liu D. AFM13: a first-in-class tetravalent bispecific anti-CD30/CD16A antibody for NK cell-mediated immunotherapy. J Hematol Oncol. 2015;8:96

20. Wolf E, Hofmeister R, Kufer P, Schlereth B, Baeuerle PA. BiTEs: bispecific antibody constructs with unique anti-tumor activity. Drug Discov Today. 2005;10(18):1237-44.

21. Hoffmann P, Hofmeister R, Brischwein K, Brandl C, Crommer S, Bargou R, et al. Serial killing of tumor cells by cytotoxic T cells redirected with a CD19-/ CD3-bispecific single-chain antibody construct. Int J Cancer. 2005;115:98104.

22. Offner S, Hofmeister R, Romaniuk A, Kufer P, Baeuerle PA. Induction of regular cytolytic $T$ cell synapses by bispecific singlechain antibody constructs on MHC class I-negative tumor cells. Mol Immunol. 2006;43:763-71.

23. Baeuerle PA, Reinhardt C. Bispecific T-cell engaging antibodies for cancer therapy. Cancer Res. 2006;69:4941-4. 
24. Stamova S, Feldmann A, Cartellieri M, Arndt C, Koristka S, Apel F, et al. Generation of single-chain bispecific green fluorescent protein fusion antibodies for imaging of antibody-induced T cell synapses. Anal Biochem. 2012;423:261-8

25. Kipriyanov SM, Moldenhauer G, Strauss G, Little M. Bispecific CD3 x CD19 diabody for T cell-mediated lysis of malignant human B cells. Int J Cancer. 1998;77:763-72.

26. Löffler A, Kufer $P$, Lutterbüse R, Zettl F, Daniel PT, Schwenkenbecher JM, et al. A recombinant bispecific single-chain antibody, CD19 $\times$ CD3, induces rapid and high lymphoma-directed cytotoxicity by unstimulated T lymphocytes. Blood. 2000;95:2098-103.

27. Topp MS, Kufer P, Gökbuget N, Goebeler M, Klinger M, Neumann S, et al Targeted therapy with the T-cell-engaging antibody blinatumomab of chemotherapy-refractory minimal residual disease in B-lineage acute lymphoblastic leukemia patients results in high response rate and prolonged leukemia-free survival. J Clin Oncol. 2011;29:2493-8.

28. Hu J, Kinn J, Zirakzadeh AA, Sherif A, Norstedt G, Wikström AC, et al. The effects of chemotherapeutic drugs on human monocyte-derived dendritic cell differentiation and antigen presentation. Clin Exp Immunol. 2013;172:490-9.

29. Rummel MJ, Niederle N, Maschmeyer G, Banat GA, von Grünhagen U, Losem C, et al. Bendamustine plus rituximab versus CHOP plus rituximab as first-line treatment for patients with indolent and mantle-cell lymphomas: an open-label, multicentre, randomised, phase 3 non-inferiority trial. Lancet. 2013;381:1203-10

30. Hiddemann W, Kneba M, Dreyling M, Schmitz N, Lengfelder E, Schmits R, et al. Frontline therapy with rituximab added to the combination of cyclophosphamide, doxorubicin, vincristine, and prednisone (CHOP) significantly improves the outcome for patients with advanced-stage follicular lymphoma compared with therapy with CHOP alone: results of a prospective randomized study of the German Low-Grade Lymphoma Study Group. Blood. 2005;106:3725-32.

31. Wei L, Dongmei F, Ming Y, Ruizan S, Yan Y, Linlin J, et al. Disulfide-stabilized diabody antiCD19/antiCD3 exceeds its parental antibody in tumor-targeting activity. Cell Oncol. 2012;35:423-34.

32. Osada T, Hsu D, Hammond S, Hobeika A, Devi G, Clay TM, et al. Metastatic colorectal cancer cells from patients previously treated with chemotherapy are sensitive to T-cell killing mediated by CEA/CD3-bispecific T-cellengaging BiTE antibody. Br J Cancer. 2010;102:124-33.

33. Tretter CP, Lewis LD, Fisher J, Waugh MG, Ernstoff MS. Taxanes synergize with the bispecific antibody MDXH447 to enhance antibody-dependent cell-mediated cytotoxicity. J Chemother. 2003;15:472-9.

34. Li W, Fan D, Yang M, Yan Y, Shi R, Cheng J, et al. Cytosine arabinoside promotes cytotoxic effect of $\mathrm{T}$ cells on leukemia cells mediated by bispecific antibody. Hum Gene Ther. 2013;24:751-60.

35. Bassan R, Hoelzer D. Modern therapy of acute lymphoblastic leukemia. J Clin Oncol. 2011;29:532-43.

36. Emens LA. Chemoimmunotherapy. Cancer J. 2010;16:295-303.

37. Vereecque R, Saudemont A, Quesnel B. Cytosine arabinoside induces costimulatory molecule expression in acute myeloid leukemia cells. Leukemia. 2004;18:1223-30.

38. Molldrem JJ, Lee PP, Wang C, Felio K, Kantarjian HM, Champlin RE, et al. Evidence that specific T lymphocytes may participate in the elimination of chronic myelogenous leukemia. Nat Med. 2000;6:1018-23.

39. Rezvani K, Grube M, Brenchley JM, Sconocchia G, Fujiwara H, Price DA, et al. Functional leukemia-associated antigen-specific memory CD8+ T cells exist in healthy individuals and in patients with chronic myelogenous leukemia before and after stem cell transplantation. Blood. 2003;102:2892-900.

40. van der Most RG, Curie A, Cleaver A, Salmons J, Nowak AK, Mahendran S, et al. Cyclophosphamide chemotherapy sensitizes tumor cells to TRAlLdependent CD8+ T cell-mediated immune attack resulting in suppression of tumor growth. PLoS One. 2009;4:e6982

41. Zhu J, Paul WE. CD4 T cells: fates, functions, and faults. Blood. 2008;112:1557-69.

42. Seo N, Tokura Y. Downregulation of innate and acquired antitumor immunity by bystander gammadelta and alphabeta T lymphocytes with Th2 or Tr1 cytokine profiles. J Interferon Cytokine Res. 1999;19:555-61.

43. Krupka C, Kufer P, Kischel R, Zugmaier G, Bögeholz J, Köhnke T, et al. CD33 target validation and sustained depletion of AML blasts in long-term cultures by the bispecific T-cell-engaging antibody AMG 330. Blood. 2014;123:356-65.
44. Laszlo GS, Gudgeon CJ, Harrington KH, Dell'Aringa J, Newhall KJ, Means GD, et al. Cellular determinants for preclinical activity of a novel CD33/CD3 bispecific T-cell engager (BiTE) antibody, AMG 330, against human AML. Blood. 2014;123:554-61.

45. Aigner M, Feulner J, Schaffer S, Kischel R, Kufer P, Schneider K, et al. T lymphocytes can be effectively recruited for ex vivo and in vivo lysis of AML blasts by a novel CD33/CD3-bispecific BiTE antibody construct. Leukemia. 2013;27:1107-15.

46. Kritas SK, Saggini A, Cerulli G, Caraffa A, Antinolfi P, Pantalone A, et al. Interrelationship between IL-3 and mast cells. J Biol Regul Homeost Agents. 2014;28:17-21.

47. Maude SL, Barrett D, Teachey DT, Grupp SA. Managing cytokine release syndrome associated with novel T cell-engaging therapies. Cancer J. 2014;20(2):119-22.

48. Klinger M, Brandl C, Zugmaier G, et al. Immunopharmacologic response of patients with B-lineage acute lymphoblastic leukemia to continuous infusion of T cell-engaging CD19/CD3-bispecific BiTE antibody blinatumomab. Blood. 2012;119:6226-33.

49. Chen L, Flies DB. Molecular mechanisms of T cell co-stimulation and co-inhibition. Nat Rev Immunol. 2013;13:227-42.

50. Shi L, Chen S, Yang L, Li Y. The role of PD-1 and PD-L1 in T-cell immune suppression in patients with hematological malignancies. J Hematol Oncol. 2013;6:74.

51. Lee DW, Barrett DM, Mackall C, et al. The future is now: chimeric antigen receptors as new targeted therapies for childhood cancer. Clin Cancer Res. 2012;18:2780-90.

52. Urbanska K, Lynn RC, Stashwick C, Thakur A, Lum LG, Powell DJ Jr. Targeted cancer immunotherapy via combination of designer bispecific antibody and novel gene-engineered T cells. J Transl Med. 2014;12:347-59

53. Ailles LE, Gerhard B, Kawagoe H, Hogge DE. Growth characteristics of acute myelogenous leukemia progenitors that initiate malignant hematopoiesis in nonobese diabetic/severe combined immunodeficient mice. Blood. 1999;94:1761-72

\section{Submit your next manuscript to BioMed Central and take full advantage of:}

- Convenient online submission

- Thorough peer review

- No space constraints or color figure charges

- Immediate publication on acceptance

- Inclusion in PubMed, CAS, Scopus and Google Scholar

- Research which is freely available for redistribution 